\title{
Regulation of Growth Cone Behavior by Calcium
}

\author{
S. B. Kater' and L. R. Mills ${ }^{1,2}$ \\ 1Program in Neuronal Growth and Development, Department of Anatomy and Neurobiology, Colorado State University, \\ Fort Collins, Colorado 80523 and 2 Playfair Neuroscience Unit, Toronto Western Hospital, Toronto, Ontario, \\ Canada M5T 2S8
}

\section{A Model for Calcium Regulation of Growth Cone Behavior}

Few structures within the nervous system have received more attention than the neuronal growth cone. Initially named by Ramon y Cajal (1890), who recognized its dynamics and importance in histological sections, the growth cone plays essential roles in the development, repair, and modification of neuronal circuitry. Growth cones have a diverse repertoire of behaviors (Fig. 1). These behaviors underlie the more complex processes of neurite elongation, pathfinding, and selective synaptogenesis. Thus, a fundamental concern of developmental neurobiology is the definition of environmental and intracellular cues that regulate growth cone behavior.

In this essay, we will consider the role of intracellular calcium in the regulation of growth cone behaviors. The impetus for envisaging such a role was provided by the elucidation of the calcium hypothesis of the control of secretion (Douglas, 1974, 1976) and synaptic transmission (Katz and Miledi, 1965; Katz, 1969; Llinas, 1979). Accordingly, we put forward a working hypothesis that stated, "if [intracellular] calcium falls below an optimal level, or rises significantly above it, growth cone motility and neurite outgrowth are inhibited" (Kater et al., 1988a).

\section{Early Studies}

The first suspicions that intracellular calcium levels were important in the regulation of neurite elongation were based on experiments using calcium channel blockers, calcium ionophores, and depolarizing agents such as elevated potassium. Schubert et al. (1978) first implicated calcium in the regulation of neurite outgrowth, and Koike (1983) later made this link for neurite initiation. Suspected parallels with synaptic transmission led Llinas (1979) to suggest that intracellular calcium plays a major regulatory role in growth cone motility and neurite outgrowth. The additional observations that actively motile growth cones have inwardly directed calcium currents that are absent from their immotile counterparts (Anglister et al., 1982; Cohan et al., 1985) provided strong impetus to test the role of calcium in growth cone behavior.

We wish to thank Drs. J. Bamburg, C. S. Cohan, D. J. Goldberg, J. I. Goldberg, P. B. Guthrie, J. J. Jensen, P. Letourncau, V. Rchder, M. Schmidt, and R. Davenport for their critical input. We also thank Dr. Gunther Stent for his particularly valuable review of the manuscript. We thank D. Giddings for the illustrations. This work was supported by NIH Grants NS24683, NS26819, and NS28323.

Correspondence should be addressed to S. B. Kater at the above address.

Copyright (C) 1991 Society for Neuroscience 0270-6474/91/110891-09\$03.00/0
The idea that a causal relationship exists between intracellular calcium and growth cone behavior was controversial even in its earliest days. For instance, addition of inorganic calcium channel blockers to the growth medium was reported to inhibit neurite outgrowth (Nishi and Berg, 1981; Suarez-Isla et al., 1984). The finding that this inhibition could be reversed by moderate increases in extracellular calcium levels led to the suggestion that "outgrowth requires an optimal level of extracellular calcium" (Suarez-Isla et al., 1984). However, other studies indicated neurite outgrowth could occur not only in the presence of calcium channel blockers (Letourneau and Wessels, 1974), but also in the absence of extracellular calcium (Bixby and Spitzer, 1984). Moreover, treatments expected to raise intracellular calcium levels were reported to increase neurite outgrowth in some cases (Hinnen and Monard, 1980; Nishi and Berg, 1981; Anglister et al., 1982) and to inhibit it in others (Haydon ct al., 1984; Suarez-Isla et al., 1984; see also Hantaz-Ambroise and Trautmann, 1989; Robson and Burgoyne, 1989). With the hindsight provided by more recent results, it is clear that such studies were unable to address a critical question: What effect did the experimental manipulations actually have on intracellular calcium concentrations?

With the development of the calcium indicator fura-2 (Grynkiewicz et al., 1985; Tsien, 1988), it became possible to determine the relationship between intracellular and extracellular calcium levels. Though a powerful tool, the limitations of this method must be kept in mind. Fura-2, a buffer, is not innocuous, and its signal is potentially limited to particular regions (e.g., submembranous changes may not be registered) or contaminated by spurious contributions from organelles. These and other limitations (Tsien, 1988, 1989) notwithstanding, several laboratories have now made direct measurement of free calcium levels within normally behaving growth cones.

\section{Neuronal Calcium Homeostasis}

Do treatments expected to alter intracellular calcium levels actually do so? Three examples from studies using the indicator fura-2 to assay intracellular calcium illustrate that neurons can compensate homeostatically for experimental perturbations intended to produce sustained changes in intracellular calcium levels. The neurons respond as if, in classical physiological terms, there is a calcium "set point"; despite continuous perturbation, neurons frequently restore calcium to near basal levels (Fig. 2). Because intracellular calcium levels are controlled by numerous different mechanisms (Baker, 1986; Carafoli, 1987; McBurney 


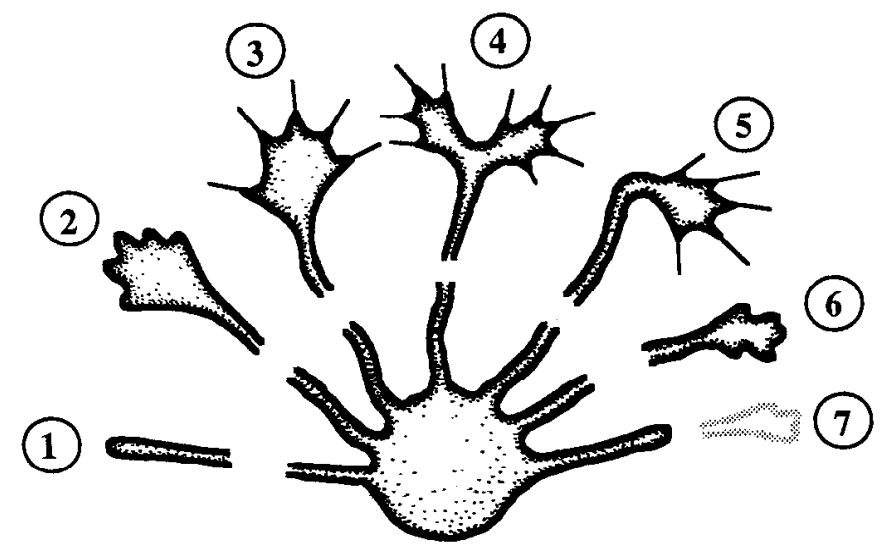

Figure 1. A schematic representation of neuronal growth cone behaviors during events such as pathfinding and circuit formation. These behaviors depend upon the intrinsic state of the neuron and the environment that the growth cone encounters. 1. Outgrowth in the absence of filopodia and lamellipodia is observed both in cell culture and in vivo. 2, Outgrowth with a distinct lamellipodium but without filopodia. 3 , The most commonly encountered form: a broad flattened lamellipodium with many filopodia. The number and length of filopodia, as well as the extent of the veil, are highly varied. 4, Branching is observed, both spontaneous and in response to evoked stimuli. 5, Turning, evoked or spontaneous, is observed both in cell culture and in vivo. 6, Arrested forms of growth cones can be observed with, or without, filopodia extended. These arrests may be permanent or may represent transient pauses in the motility of the growth cone. 7 , Growth cone retraction as in response to a "stop signal."

and Neering, 1987), several processes may be involved in this compensatory response.

\section{Evoked rises in intracellular calcium levels}

Intracellular calcium levels can be significantly raised by the application of the calcium ionophore A23187 to the growth medium. Direct measurements of intracellular calcium show that low to moderate doses of A23187 do produce a substantial rise in intracellular calcium levels. In many cells, however, this rise is transient; intracellular calcium levels peak and, despite the continued presence of ionophore, subsequently decline towards the original basal level (Fig. 2). $\mathrm{A} \mathrm{Na}+\mathrm{Ca}^{2+}$ exchanger is likely responsible for this regulation. The efficiency of this mechanism, however, is quite different in various cell types and even in the same identified neuron at different developmental states (Mattson et al., 1989a; Mills and Kater, 1990).

Another example of a compensatory response to rises in intracellular calcium levels is provided by the inhibition of neurite outgrowth in mouse dorsal root ganglion neurons (DRGs) by electrical activity (Fields et al., 1990a,b; discussed in more detail below). Electrical activity initially inhibits outgrowth; however, outgrowth resumes after prolonged stimulation. Direct measurements of intracellular calcium levels over this longer time course show that the stimulus that produces a significant rise in calcium early in the experiment (and thus causes inhibition of outgrowth) no longer produces the same large calcium rise later in the experiment, presumably due to as yet unidentified homeostatic mechanisms. Increasing stimulus frequency, on the other hand, even at this later time, inhibits outgrowth and does produce a large rise in intracellular calcium. From examples such as these, it is clear that the simple view of stimulus-response must also incorporate a consideration of cellular compensatory activities.

\section{Experimental decreases in intracellular calcium levels}

In accordance with the expectations of earlier investigators, application of calcium channel blockers or elimination of extracellular calcium can produce a decrease in intracellular calcium levels. It is now clear that such decreases may be only transient. In both snail neurons and pyramidal neurons from rat hippocampus, intracellular calcium concentrations return to rest levels within less than $1 \mathrm{hr}$ after an initial fall in response to application of calcium-free medium (Kater et al., 1989; Rehder et al., 1991). This indicates that neurons compensate for the reduced (leak) calcium influx by releasing calcium from internal stores. It should be noted again, however, that the efficiency of calcium homeostasis is both cell-type and cell-state specific (Mattson et al., 1989a; Mills and Kater, 1990).

The above examples indicate that calcium homeostasis is a very powerful process and that the interpretation of perturbations that attempt to modify the calcium set point (Guthrie et al., 1988) may therefore be subject to error. Indeed, the growth cones of some neurons continue to elongate under calcium-free external conditions (Bixby and Spitzer, 1984; Campenot and Dracker, 1989). Perhaps such neurons have the capacity to compensate for reductions in intracellular calcium levels. Alternatively, in these cases neurite outgrowth may be regulated by other, calcium-independent, mechanisms (Kater et al., 1988a; Mattson et al., 1988a,b; Lankford and Letourneau, 1991).

\section{Experimentally Evoked Growth Cone Behaviors}

There have been many attempts to evoke experimentally one or more of the different growth cone behaviors depicted in Figure 1. Several of these, examining turning or stopping behavior, have led to direct tests of a regulatory role for intracellular calcium.

Turning

Marsh and Beams (1946) found that neurite outgrowth turns in the direction of an imposed electric field. This experiment was extended to direct observations of growth cone turning by Poo and his colleagues (Patel and Poo, 1982, 1984). McCaig (1989) has now linked turning behavior to calcium influx; growth cone turning evoked by discrete electric fields is prevented by calcium channel blockers. Using a stimulus more clearly related to normal development, Gundersen and Barrett (1980) found that the growth cones of chick DRG neurons can orient towards a source of NGF. This turning is apparently dependent upon release of calcium from intracellular stores, rather than calcium influx. However, further experiments indicated that turning can also be evoked by local increases in intracellular calcium produced by influx: In the presence of calcium ionophore, growth cones orient towards a point source of extracellular calcium. This study represents one of the best demonstrations of the idea that physiologically relevant stimuli producing changes in growth cone behavior are linked to changes in intracellular calcium levels. These examples of galvanotropism and chemotropism are particularly noteworthy because they represent some of the most subtle of growth cone behaviors that have thus far been experimentally manipulated.

\section{Stopping}

Patterson (1988) discussed the importance of "stop signals" for neurite outgrowth. Cues that halt growth cone advance include both bound and soluble environmental cues and intrinsic electrical activity (Fig. 3). 


\section{Increased Calcium}
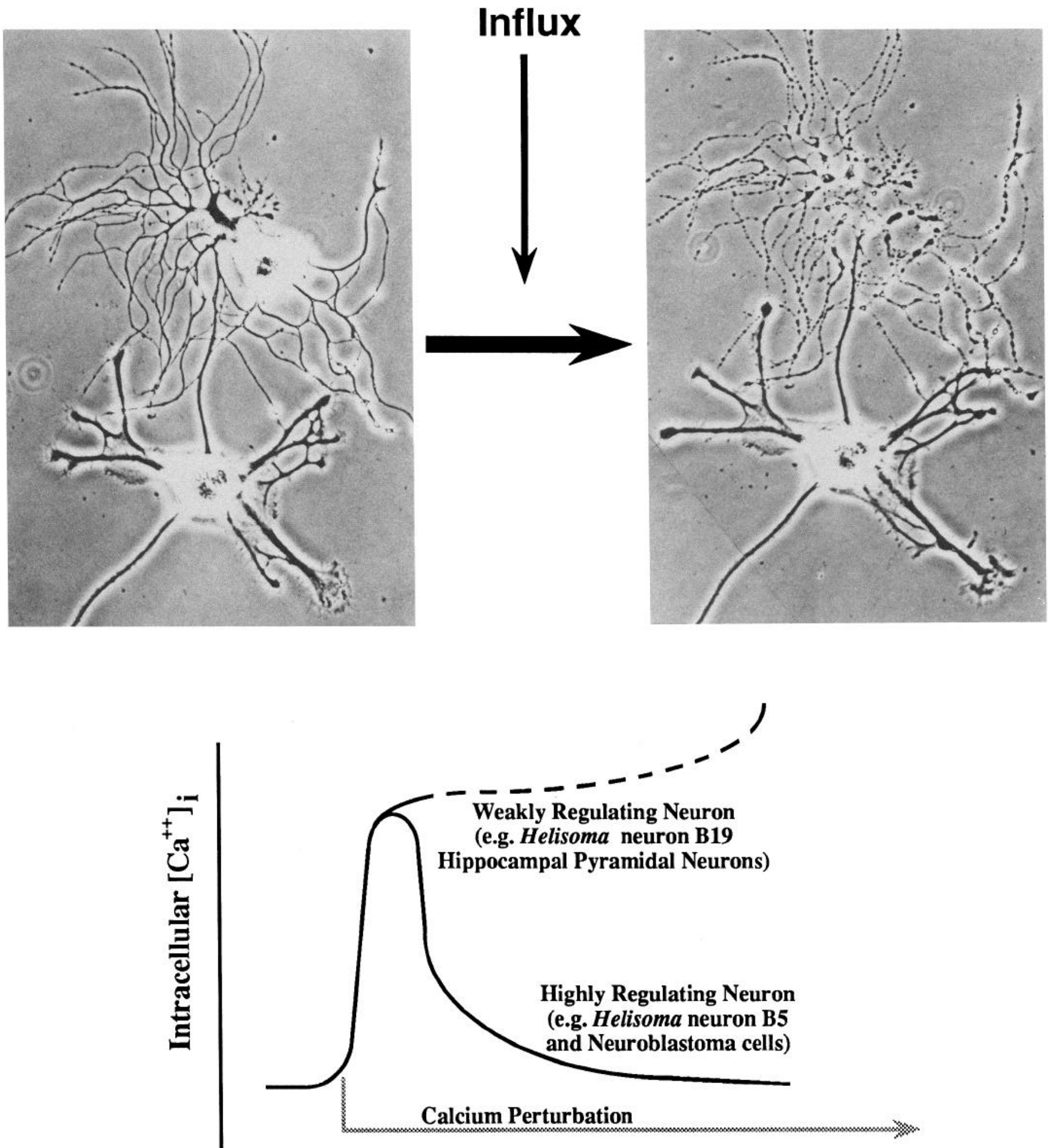

\section{Time}

Figure 2. Perturbations in intracellular calcium levels can change growth cone behavior and survival of neurons. In the upper portion of the figure, photomicrographs show a Helisoma neuron B5 (lower neuron) and a Helisoma neuron B19 (upper neuron). In response to the application of A23187, the growth cones of neuron B5 remain motile, and elongation continues, albeit diminished, while neuron B19 is killed. These results are generalized in the graph below, which indicates that highly regulating neurons such as Helisoma neuron B5 and neuroblastoma cells respond to the calcium ionophore A23187 with a transient rise in intracellular calcium levels: After an initial increase, calcium levels are subsequently restored towards basal levels by homeostatic mechanisms. In weakly regulating neurons such as Helisoma neuron B19 and hippocampal pyramidal neurons exposed to the same dose of ionophore, intracellular calcium levels continue to rise until cell death eventually occurs. This neuron-specific response to a calcium challenge illustrates the necessity of understanding the calcium-clearance mechanisms of individual neurons under investigation. 

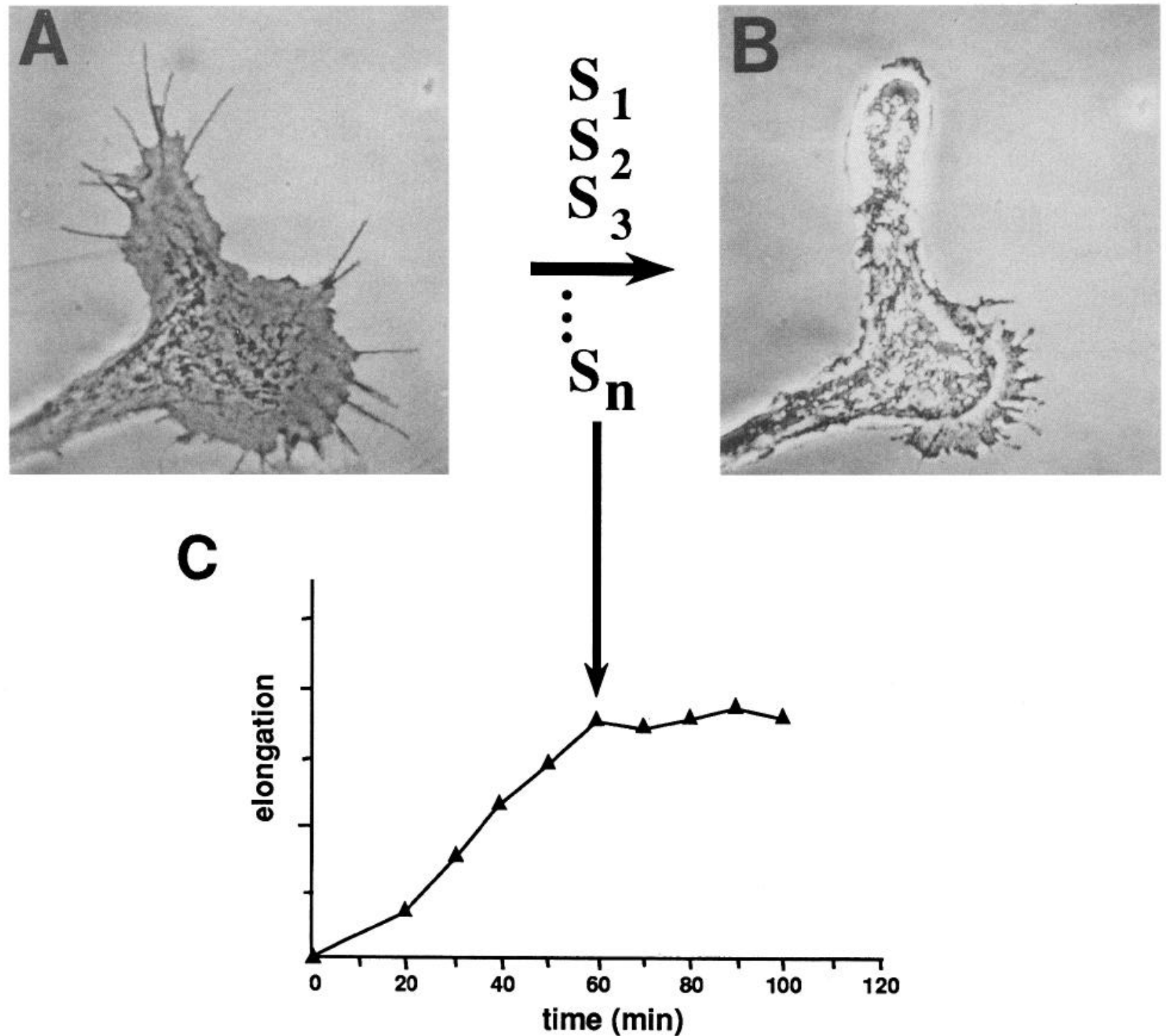

Figure 3. Stop signals. Actively growing endings are characterized by a large lamellipodium and numerous filopodia. Different signals, including action potentials $\left(S_{1}\right)$, depolarization $\left(S_{2}\right)$, neurotransmitters $\left(S_{3}\right)$, and other as yet unidentified cues $\left(S_{n}\right)$, can transform active growth cones $(A)$ to immobile endings $(B)$. Following application of any of these stop signals, the lamellipodium and filopodia retract, and neurite elongation is inhibited (C).

\section{Environmental cues}

Though many bound molecules influence growth cone behavior, few have been investigated for their effects upon intracellular calcium. However, calcium measurements during growth cone collapse mediated by cell-cell contact (e.g., Kapfhammer and Raper, 1987; Ivins and Pittman, 1989) show no change in intracellular calcium concentration (Ivins et al., 1990). In contrast, application of antibodies to two defined cell-surface molecules, $\mathrm{L} 1$ and N-CAM, both evoke rises in intracellular calcium concentration in PC12 cells (Schuch et al., 1989). A more complete picture of the relationship of bound molecules to intracellular calcium is clearly required, though the work of Ivins et al. (1990) does demonstrate an alternate, calcium-independent, path for evoking growth cone collapse.

Work with an important class of diffusable molecules, the neurotransmitters, provided the first direct evidence that rises in intracellular calcium levels inhibit growth cone motility. 5-HT exerts a highly selective and neuron-specific inhibition of the outgrowth of particular identified neurons of the snail Helisoma (Haydon et al., 1984, 1987). Similarly, glutamate immobilizes growth cones of dendrites of cultured hippocampal pyramidal neurons while leaving growth cones of axons on the same neuron relatively unaffected (Mattson et al., 1988c). In both cases, a near collapse of the growth cone occurs in the presence of a sufficient concentration of the respective excitatory neurotransmitters. Inhibitory neurotransmitters, by contrast, namely $\mathrm{ACh}$ in the case of Helisoma neurons (McCobb and Kater, 1988a; McCobb et al., 1988) and GABA in the case of the hippocampal pyramidal neurons (Mattson and Kater, 1988), are essentially without effect on growth cone behavior. However, when present together with the corresponding excitatory neurotransmitter, they negate the usual outgrowth inhibitory effects. These findings suggested that the growth inhibitory effects of neurotransmitters might be mediated by membrane potential and the consequent opening of voltage-sensitive calcium channels. To test this idea, 
McCobb and Kater (1988b) held the membrane potential of growth cones in Helisoma neurons hyperpolarized so that the excitatory transmitter did not cause significant depolarization. Such conditions completely negate the growth-inhibitory effects of 5-HT.

Direct measurements of intracellular calcium levels within the growth cones of Helisoma neurons revealed that addition of 5-HT produces a large rise in intracellular calcium concentration. The presence of $\mathrm{ACh}$, which negates the outgrowth inhibition by $5-\mathrm{HT}$, blocks this rise in calcium (McCobb and Kater, 1988a) levels. Similar results were obtained from hippocampal neurons whose calcium levels rise with glutamate application. The presence of GABA, along with its potentiator diazepam, blocks the calcium rises normally seen in response to glutamate (Mattson and Kater, 1988). These findings support the idea that rises in intracellular calcium levels are inhibitory to growth cone motility (Kater et al., 1988b, 1989).

\section{Action potentials}

Electrical activity can also act as a growth cone stop signal. The generation of action potentials inhibits neurite outgrowth in identified neurons of Helisoma (Cohan and Kater, 1986), with different identified neurons requiring different patterns of action potentials for inhibition (Cohan, 1990). As expected, action potentials produce a rise in intracellular calcium levels that is correlated with the inhibition of outgrowth. This idea has been extended by work on mouse DRGs (Fields et al., 1990a,b) which confirms that initiation of action potentials inhibits growth cone motility in a calcium-dependent fashion and also suggests that calcium homeostatic mechanisms can override these growth cone-inhibiting effects (as previously discussed).

\section{Ionophore}

The idea that an increase in intracellular calcium can inhibit growth cone motility has also been examined using calcium ionophores. While clearly nonphysiological, the use of ionophore offers certain experimental advantages: It produces a uniformly distributed and noninactivating permeability to calcium. The activity of growth cones of Helisoma neurons and hippocampal neurons can be selectively regulated by the addition of the calcium ionophore A23187. Exposure to low levels of A23187 can completely inhibit neurite outgrowth. At higher doses it can prune arbors, and at still higher levels, cell death ensues (Mattson et al., 1988c). In addition, axonal growth cones of hippocampal neurons are far less sensitive to A23187 than are their dendritic counterparts. Most recently, Lankford and Letourneau $(1989,1991)$ linked the growth-inhibitory effects of A23187 to changes in the cytoskeletal machinery underlying neurite elongation.

\section{The Integration of Multiple Stimuli}

Single stimuli can clearly evoke specific growth cone behaviors in simplified cell culture systems. In vivo, however, the growth cone must integrate information from multiple cues (Mills and Kater, 1989; Kater and Guthrie, 1990). The integrative capacity of the growth cone is illustrated in Figure 4: Individual stimuli, which have distinct effects on their own, act in concert when applied to Helisoma growth cones. As previously discussed, ACh can negate the rise in intracellular calcium levels, and the subsequent inhibition of neurite outgrowth normally elicited by 5-HT (McCobb et al., 1988). A third stimulus, action potentials, overrides both neurotransmitter stimuli: A large calcium rise

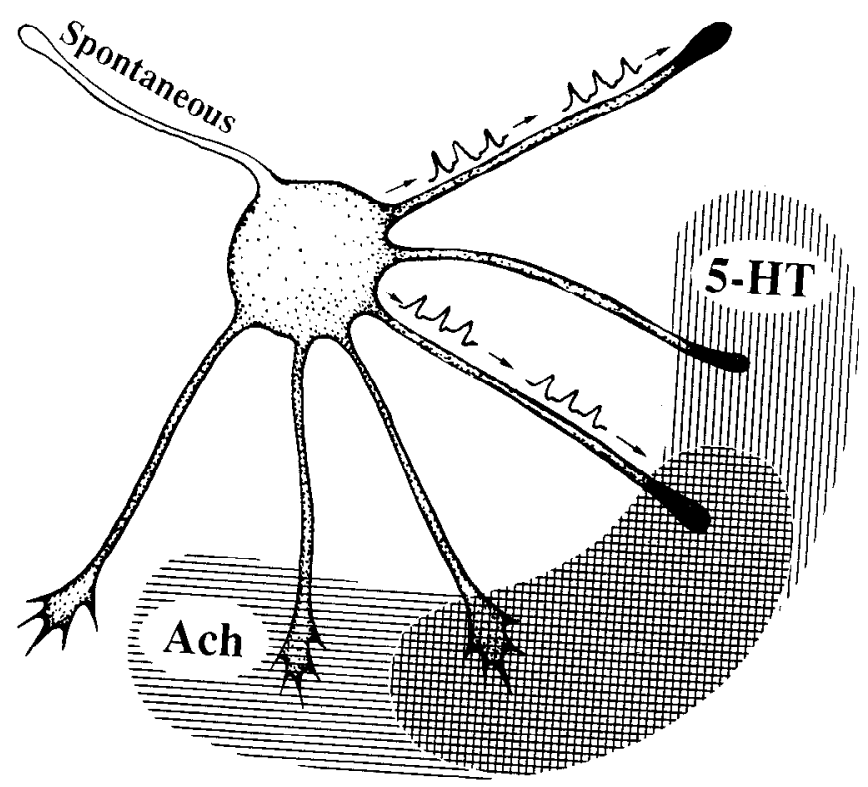

Figure 4. The integration of multiple stimuli in the regulation of growth cone behavior. In the absence of particular stimuli, individual growth cones either continue outgrowth at a particular calcium level (light stippling) or spontaneously terminate outgrowth accompanied by decreases in intracellular calcium (no stippling). The generation of action potentials abruptly inhibits neurite outgrowth, as does the presence of $5-H T$ through a rise in intracellular calcium (solid areas). The presence of $A C h$ has no noticeable effects on growth cone motility or calcium levels but can protect against 5-HT-induced inhibition of growth cone motility and rises in intracellular calcium levels. However, in the presence of both ACh and 5-HT, the additional stimulus of action potentials raises intracellular calcium and results in an abrupt termination of outgrowth. This illustration, taken from results obtained with Helisoma neurons, exemplifies the kinds of conditions likely found in vivo where multiple stimuli are integrated by the active neuronal growth cone.

occurs, and outgrowth is abruptly terminated (McCobb and Kater, 1988b). Thus, for combinations of stimuli, the integration of intracellular calcium levels results in a functional decision, to continuc, or to cease, growth cone motility.

\section{Spontaneous Growth Cone Behaviors}

In hippocampal neurons (Connor, 1986), as well as in Helisoma neurons (Cohan et al., 1987), that have spontaneously stopped growing, the level of intracellular calcium is lower than in their growing counterparts. Furthermore, the range of intracellular calcium levels associated with outgrowth is different in different identified neurons. These observations, and those made using calcium channel blockers, and (nominal) calcium-free media, suggested that if calcium levels fall below a critical range, outgrowth is inhibited (Kater et al., 1988a). In view of the evidence provided above that experimentally evoked rises in calcium levels above a critical range may also inhibit outgrowth, it would follow that there is a permissive range of intracellular calcium for growth cone activity.

It should be noted, however, that Silver et al. (1989) have correlated spontaneous growth cone behavior and intracellular calcium levels in a neuroblastoma cell line and that their results are not in complete agreement with those described above. They showed that spontaneous increases in intracellular calcium in active growth cones do indeed inhibit neurite extension, but that calcium levels in quiescent growth cones are no lower than 


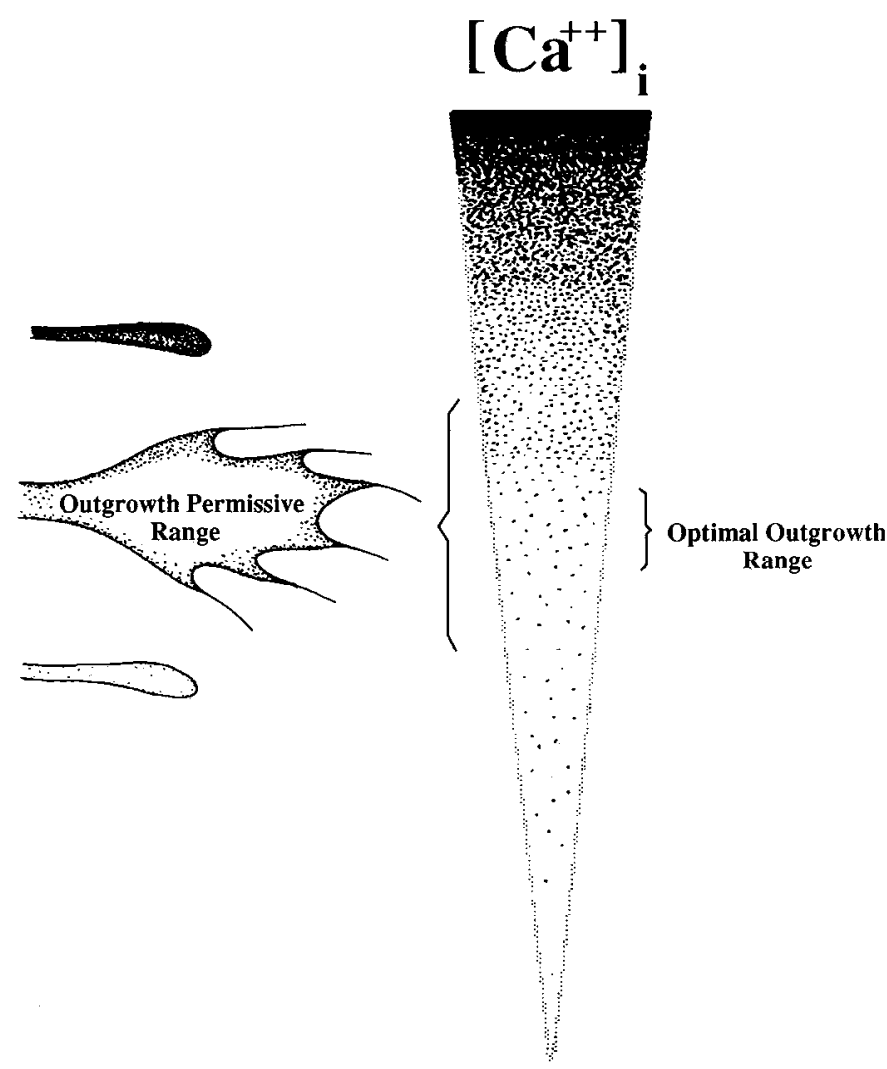

Figure 5. A model for regulation of growth cone motility by intracellular calcium. Neurite elongation occurs over a range of intracellular calcium concentrations, the outgrowth-permissive range (moderate stippling). Within this range there are graded effects of changes in intracellular calcium on neurite outgrowth; maximal outgrowth occurs specifically within a narrow optimal outgrowth range. At calcium concentrations above, or below, this optimal level, but still within the overall permissive range, outgrowth can still occur but is reduced. At calcium levels above the permissive range (heavy stippling), filopodia and lamellipodia retract, and elongation ceases. At calcium levels below the permissive range (light stippling), outgrowth is inhibited, as could occur, for example, during the conversion of an actively growing ending to a presynaptic ending. The effects of a stimulus that changes intracellular calcium will depend upon both the initial rest calcium level and the magnitude of that change.

in their motile counterparts. The reason for this apparent discrepancy with the results of Connor (1986) and Cohan et al. (1987) may lie in the fact that other, calcium-independent, mechanisms can also mediate transitions between growing and nongrowing states (Mattson et al., 1988a,b; Lankford and Letourneau, 1991). Thus, though changes in intracellular calcium levels are not necessary, they appear to provide a sufficient condition for a change in growth cone behavior to occur.

\section{Titration of Intracellular Calcium Levels}

Direct demonstrations of the existence of a permissive range of calcium concentration for growth cone motility are difficult to accomplish due to the high capacity of neurons for calcium homeostasis. Tolkovsky et al. (1990) attempted to overcome this difficulty by "clamping" calcium levels while monitoring neurite outgrowth. They suggested that constant calcium conditions (at least within the cell body) are sufficient for neurite elongation; calcium rises, or transients, are not required, though a decline in rest calcium levels is sufficient to inhibit outgrowth.
The relationship between specific calcium levels and growth cone activity has been directly addressed by Letourneau and colleagues. Their initial studies (Lankford and Letourneau, 1989) investigated the effects of changes in intracellular calcium levels on growth cone behavior and ultrastructure of chick DRG neurons. Increases in calcium levels (the addition of A23187), or decreases in calcium levels (removal of extracellular calcium), result in cessation of neurite outgrowth. Both effects are reversible. These results, which they attribute to the action of calcium on the neuronal cytoskeleton, further suggest that there is a permissive range of intracellular calcium for the organization of actin filaments and, consequently, for growth cone motility. Recently, in a study characterizing the calcium sensitivity of growth cone behavior, they made a direct test of a permissive range by titrating intracellular calcium within the growth cone using A23187 to permeabilize the cells to calcium. The calcium buffer BAPTA was then used to set the external and, accordingly, internal, calcium levels (Lankford and Letourneau, 1991). They found that the growth cone is highly sensitive to changes in intracellular calcium levels; when calcium levels fall below 200 nM or rise above $300 \mathrm{nM}$, motility and outgrowth cease. Furthermore, experimental alterations in calcium levels by as little as $50 \mathrm{~nm}$ have effects: Growth cone motility and neurite outgrowth can be promotcd or inhibitcd by titrating intracellular calcium.

This investigation by Lankford and Letourneau (1991) also provides evidence of calcium-independent pathways for growth cone regulation. Activation of protein kinase $\mathrm{C}$ by addition of phorbol ester was found to regulate growth cone behavior, but not through effects on calcium or the cytoskeleton. Growth cones spontaneously recovered from the growth-inhibitory effects of phorbol ester, indicating the presence of compensatory mechanisms, as exist for calcium. The results of this study are similar to results in rat hippocampal neurons where phorbol ester-mediated changes in neurite outgrowth were found to be independent of intracellular calcium changes (Mattson et al., 1988a).

\section{The Present View of Calcium as a Regulator of Growth Cone Behavior}

The initial model postulated a permissive range of intracellular calcium levels for neurite outgrowth. This model can be refined in light of subsequent work to incorporate the idea that there are graded effects of calcium concentration on growth cone behavior (Fig. 5): Activity (e.g., outgrowth) occurs over a range of calcium concentrations, with maximal activity occurring at an optimal level within this generally permissive range. This expanded model resembles other graded calcium-dependent processes, such as synaptic transmission (Katz, 1969; Llinas, 1979), insulin-stimulated glucose transport (Draznin et al., 1987), catecholine secretion from the adrenal medulla (Knight, 1986), and neuronal survival (Koike et al., 1989). Many of these processes also display a similar dependence on an optimal calcium level.

\section{An optimal level within the permissive range}

The refined model implies that, unless one takes into consideration both the existing rest calcium levels and the magnitude of the change in calcium level, one can not predict a priori whether a given stimulus will have growth-promoting or growthinhibiting effects. Depending upon rest calcium levels, a given stimulus could have opposite effects. For example, within a neuron that is growing slowly as a result of permissive but suboptimal levels of intracellular calcium, a given stimulus could 
raise intracellular calcium closer to the optimal level and, accordingly, stimulate neurite outgrowth. On the other hand, within a neuron that is already growing at a maximal rate (becausc of an optimal calcium level), the same stimulus could raise the calcium level above the permissive range and inhibit motility. This model may explain why both ionophore (Hinnen and Monard, 1980; Anglister et al., 1982; Mattson and Kater, 1987; Goldberg, 1988; Mills and Kater, 1990) and electrical depolarization (Nishi and Berg, 1981; Anglister et al., 1982; Cohan and Kater, 1986; Hantaz-Ambroise and Trautmann, 1989; Fields et al., 1990a; see also Robson and Burgoyne, 1989; Cohan, 1990) can both promote and inhibit neurite outgrowth.

Clearly, the emerging picture is complex (Fig. 6). In addition to information on the initial and stimulated calcium levels, knowledge of other parameters, such as the rate of change of calcium levels, may also be critical. Also, clustering of calcium channels in the growth cone may provide a mechanism to produce local rises in intracellular calcium. A rise in intracellular calcium levels could be spatially inhomogeneous despite a stimulus to the entire growth cone (Silver et al., 1990). One must also take into consideration calcium homeostatic mechanisms that modulate calcium signals. Finally, though thus far established only for fibroblast growth factor (Mattson et al., 1989b), exogenous agents can modify the efficacy of calcium homeostasis.

\section{Subcellular components of the permissive range}

What sets the permissive range of intracellular calcium concentrations for neurite outgrowth (Fig. 5)? Active outgrowth undoubtedly involves insertion of membrane components (Bray, 1973), assembly and disassembly of microtubules (Schliwa et al., 1981; Bamburg et al., 1986), organization and reorganization of actin filaments (Mitchison and Kirschner, 1988), and movement of organelles (Hammerschlag et al., 1975; Forscher et al., 1987). Each of these processes may have a discrete calcium optimum that potentially overlaps those of other processes. Thus, the permissive range is a composite of the calcium optima of all of the processes that contribute to growth cone behavior.

Even in the case of a single process such as actin assembly, the calcium optima can be different in different locations. For example, titration experiments show that moderate increases in intracellular calcium cause a loss of lamellipodial actin, while filopodial actin is spared (Lankford and Letourneau, 1989, 1991). Additionally, Sobue and Kanda (1989) found calcium-sensitive and -insensitive forms of $\alpha$-actinin in different locations of the growth cone. They speculate that different ratios of calciumdependent, and calcium-independent, molecules such as $\alpha$-actinin could well provide additional means whereby the growth cones of different neurons could react differentially to the same calcium load. Finally, intermediary agents such as the calpains or calmodulin add to the loci at which calcium regulates the growth cone machinery. In the context of work previously discussed, the inhibition by 5-HT of Helisoma growth cone motility can be negated by the presence of a calmodulin antagonist (Polak et al., 1991). This indicates that the 5-HT-evoked rise in calcium levels activates calmodulin, which in turn alters some required component of growth cone motility. Similarly, the calpain blocker EST can negate the dendrite-pruning effects of A23187 in hippocampal pyramidal neurons (Song et al., 1990). In summary, there are many defined sites of calcium action, each of which may contribute to, or be critical for, a given growth cone behavior.

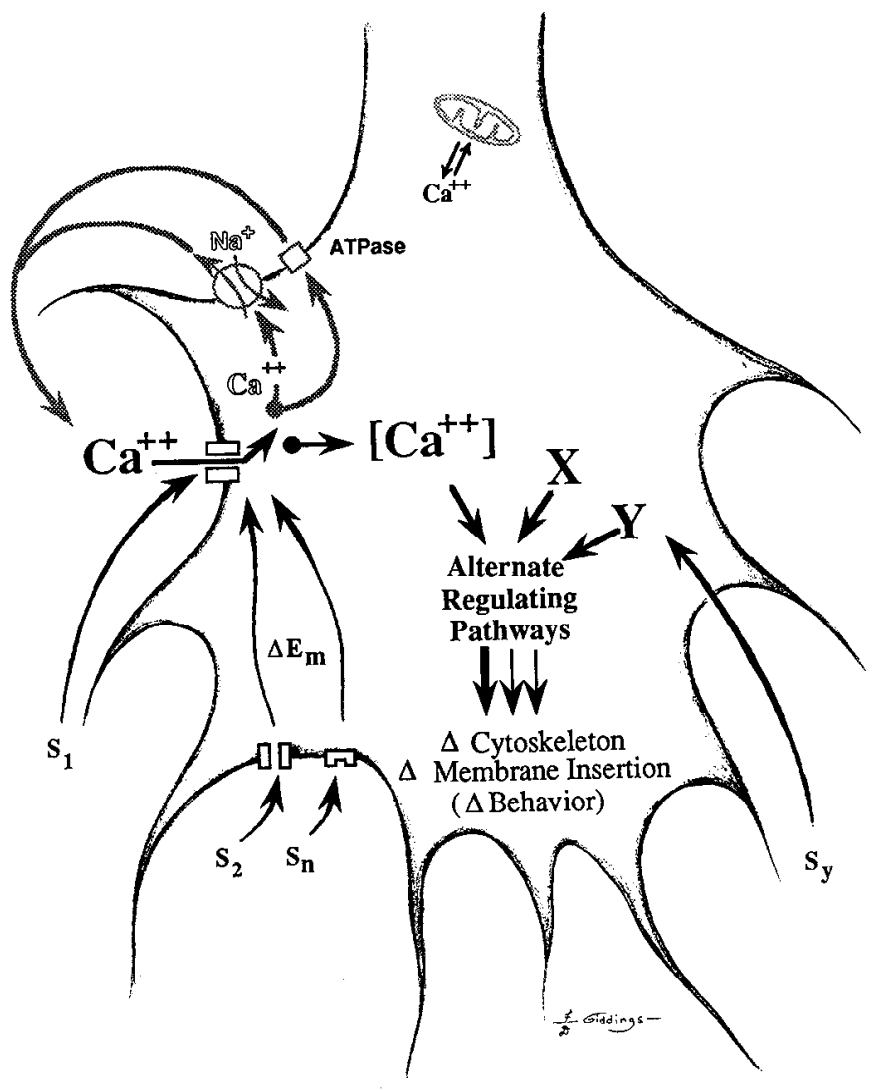

Figure 6. The present view of control of neuronal growth cone behavior by intracellular messengers. Intracellular calcium levels play a prominent role in regulating neurite outgrowth, and changes in concentration are likely to affect distinct processes such as cytoskeletal dynamics and membrane insertion. Changes in intracellular calcium levels are produced through a variety of paths, including stimuli that directly change voltage-dependent calcium channels $\left(S_{i}\right)$ and stimuli that affect other ion channels, depolarize the cell, and accordingly open voltagedependent channels $\left(S_{2}\right)$, as well as potentially through other ligandgated mechanisms $\left(S_{n}\right)$. Othcr stimuli $\left(S_{y}\right)$ affect alternate regulating pathways. Alternate paths include second messengers such as cyclic nucleotides or, eventually, inositol phosphate. Calcium levels are tightly regulated through several calcium homeostatic mechanisms, some of which are diagrammatically illustrated here, such as mitochondrial sequestration, the sodium-calcium exchanger, and an ATP-dependent mechanism.

\section{Conclusions}

A central role for intracellular calcium in the regulation of growth cone behavior has been documented by many investigators. We have made use of a model to provide a context within which to examine data from many different organisms, and neuronal cell types, in various states of development. While there is not enough overlapping information to link fully the sets of data, our current view is summarized in Figure 7. The effects of changes in intracellular calcium levels are graded: At optimal levels, outgrowth is profuse; lower or higher levels result in decreased outgrowth; still lower or higher levels reduce survival. For all of these events, it is crucial to consider that the specific calcium optimum for different components of growth cone behavior could be quite different, as indeed the optima are for different neurons, or even for the dendrites and axons of the same neuron. To this regulatory scheme, one must also add the potential modulating effects of calcium homeostatic mechanisms. 


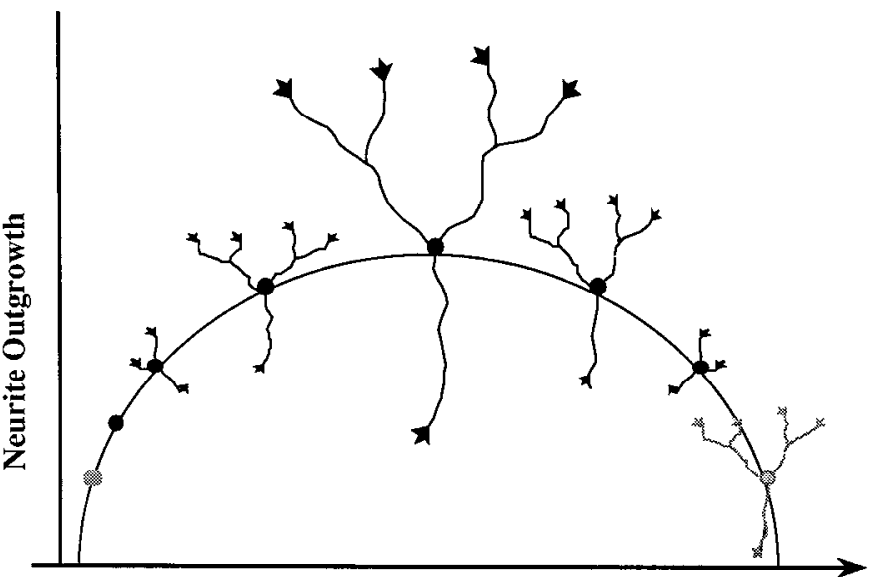

Increasing $\left[\mathbf{C a}^{++}\right]_{\mathbf{i}}$

Figure 7. Graded effect of intracellular calcium concentrations. At low calcium concentrations, neurons fail to survive. Higher calcium concentrations promote successive increases in outgrowth. These graded changes may be differentially effective on growth cones of axons and dendrites. At still higher concentrations, outgrowth decreases, and pruning of existing neurites may occur. Ultimately, at very high concentrations of intracellular calcium, neuronal cell death occurs.

Many basic questions remain, among them: Do both transient and sustained calcium signals carry information? Do calciumdependent processes change their responsiveness with time? How malleable are the separate components of calcium homeostasis? And finally, what are the relative strengths of calcium-independent regulatory paths? Calcium regulation of cellular processes is a rapidly expanding area of understanding in cell biology. Cell division (Poenie et al., 1985), pinocytosis (Prusch, 1986), exocytosis (Knight, 1986), cell migration (Marasco et al., 1980), and shape changes (Hyatt et al., 1984; Heysmann and Middleton, 1987) are all areas of major calcium involvement. In addition, a "calcium set point" with an optimal level of calcium required for neuronal survival has also been described (Koike et al., 1989; Collins et al., 1990). It remains now to sort out the parallels and generalities of calcium regulation of different processes in order to arrive at a comprehensive picture of how intracellular calcium acts in the overall regulatory framework of a neuron. The existing data on neuronal growth cone behavior suggest that an optimal range of intracellular calcium levels is a basic element of the control of neuronal development.

\section{References}

Anglister L, Farber IC, Shahar A, Grinvald A (1982) Localization of voltage-sensitive calcium channels along developing neurites: their possible role in regulating neurite elongation. Dev Biol 94:351-365.

Baker PF (1986) The sodium-calcium exchange system. Ciba Found Symp 122:73-97.

Bamburg J, Bray D, Chapman K (1986) Assembly of microtubules at the tips of growing axons. Nature 321:788-790.

Bixby JL, Spitzer NC (1984) Early differentiation of vertebrate spinal neurons in the absence of $\mathrm{Ca}^{2+}$ and $\mathrm{Na}^{+}$influx. Dev Biol 106:89-96.

Bray D (1973) Model of membrane movements in neuronal growth cones. Nature 244:93-94.

Campenot RB, Dracker DD (1989) Growth of sympathetic nerve fibers in culture does not require extracellular calcium. Neuron 3:733-743.

Carafoli E (1987) Intracellular calcium homeostasis. Annu Rev Biochem 56:395-433.

Cohan CS (1990) Frequency-dependent and cell-specific effects of electrical activity on growth cones movements of cultured Helisoma neurons. J Neurobiol 21:400-413.
Cohan CS, Kater SB (1986) Suppression of neurite elongation and growth cone motility by electrical activity. Science $232: 1638-1640$.

Cohan CS, Haydon PG, Kater SB (1985) Single channel activity differs in growing and non-growing growth cones of isolated neurons of Helisoma. J Neurosci Res 13:285-306.

Cohan CS, Connor JA, Kater SB (1987) Electrically and chemically mediated increases in intracellular calcium in neuronal growth cone. J Neurosci 7:3588-3599.

Collins F, Schmidt MF, Guthrie PG, Kater SB (1990) Sustained increases in intracellular calcium promote neuronal survival in cultured chick ciliary ganglion neurons. J Cell Biol Abst 111:244a.

Connor JA (1986) Digital imaging of free calcium changes and of spatial gradients in growing processes in single, mammalian central nervous system cells. Proc Natl Acad Sci USA 83:6178-6183.

Douglas WW (1974) Involvement of calcium in exocytosis-vesiculation sequence. In: Calcium and cell regulation (Smellie RMS, ed), pp 1-28. London: Biochemical Society.

Douglas WW (1976) The rolc of calcium in stimulus-secretion coupling. In: Stimulus-secretion coupling in the gastrointestinal tract (Goebel H, ed), pp 17-48. Baltimore: University Park.

Draznin B, Sussman K, Kao M, Lewis D, Sherman N (1987) The existence of an optimal range of cytosolic free calcium for insulinstimulated glucose transport in rat adipocytes. J Biol Chem 262: 14385-14388.

Fields RD, Neale EA, Nelson PG (1990a) Effects of patterned electrical activity on neurite outgrowth from mouse sensory neurons. J Neurosci 10:2950-2964.

Fields RD, Guthrie PB, Kater SB (1990b) Calcium homeostatic capacity is regulated by patterned electrical activity in the growth cones of mouse DRG neurons. Soc Neurosci Abstr 16:457.

Forscher P, Kaczamarek LK, Buchamnan J, Smith SJ (1987) Cyclic AMP induces changes in distribution and transport of organelles within growth cones of Aplysia bag neurons. J Neurosci 7:3600-3611.

Goldberg DJ (1988) Local role of $\mathrm{Ca}^{++}$in formation of veils in growth cones. J Neurosci 8:2596-2605.

Grynkiewicz D, Neufeld G, Schweigerer L (1985) A new generation of calcium indicators with greatly improved fluorescence properties. J Biol Chem 260:3440-3450.

Gundersen RW, Barrett JN (1980) Characterization of the turning response of dorsal root neurites towards nerve growth factor. J Cell Biol 87:546-554.

Guthrie PB, Mattson MP, Mills LR, Kater SB (1988) Calcium homeostasis in molluscan and mammalian neurons: neuron-selective set-point of calcium rest concentration. Soc Neurosci Abstr 14:582.

Hammerschlag R, Dravid AR, Chiu AY (1975) Mechanisms of axoplasmic transport: a proposed role for calcium ions. Scicnce 212: $1164-1169$.

Hantaz-Ambroise D, Trautmann A (1989) Effects of calcium ion on neurite outgrowth of rat spinal cord neurons in vitro: the role of nonneuronal cells in regulating neurite sprouting. Int $\mathrm{J}$ Dev Neurosci 7 591-602.

Haydon PG, McCobb DP, Kater SB (1984) Serotonin selectively inhibits growth cone motility and the connection of identified neurons. Science 226:561-564

Haydon PG, McCobb DP, Kater SB (1987) The regulation of neurite outgrowth, growth cone motility, and electrical synaptogenesis by serotonin. J Neurobiol 18:197-215.

Heysmann JE, Middleton CA (1987) Cell behavior: shape adhesion and motility. J Cell Sci [Suppl] 8:449.

Hinnen R, Monard D (1980) Involvement of calcium ions in neuroblastoma neurite extension. In: Control mechanisms in animal cells (Jimener de Ausa L, ed), pp 315-323. New York: Raven.

Hyatt HA, Shure MS, Begg DA (1984) Induction of shape transformation in sea urchin coelomocytes by calcium ionophore A23187. Cell Motil 4:57-71.

Ivins JK, Pittman RN (1989) Growth cone interactions in cultures of rat sympathetic neurons. Dev Biol 135:147-157.

Ivins JK, Raper JA, Pittman R (1990) Intracellular calcium levels do not change during the contact mediated collapse of chick DRG growth cones. Soc Neurosci Abstr 16:1009.

Kapfhammer JP, Raper JA (1987) Collapse of growth cone structure on contact with specific neurites in cultures. J Neurosci 7:201-212.

Kater SB, Guthrie PG (1990) The neuronal growth cone as an integrator of complex environmental information. In: The brain, Cold Spring Harbor Symposium 55. Cold Spring Harbor, NY: Cold Spring Harbor Lab. 
Kater SB, Mattson M, Cohan CS, Connor J (1988a) Calcium regulation of the neuronal growth cone. Trends Neurosci 11:315-321.

Kater SB, Guthrie PB, Mattson M, Mills LR, Zucker RS (1988b) Calcium homeostasis in molluscan and mammalian neurons: dynamics of calcium regulation. Soc Neurosci Abstr 14:582.

Kater SB, Mattson MP, Guthrie PB (1989) Calcium-induced neuronal degeneration: a normal growth cone regulating signal gone awry (?). In: Calcium, membranes, aging and Alzheimer's disease (Khachaturian ZS, Cottmann CW, Pettegrew JW, eds), Vol 568, pp 252-261. New York: New York Academy of Sciences.

Katz B (1969) The release of neural transmitter substances. Liverpool: Liverpool UP.

Katz B, Miledi R (1965) The role of calcium on actetylcholine release from motor nerve terminals. Proc R Soc Lond [Biol] 161:496-503.

Knight DE (1986) Calcium and exocytosis. Ciba Found Symp 122: 250-270.

Koike T (1983) Nerve growth factor induced neurite outgrowth of rat pheochromocytoma PC12 cells: dependence upon extracellular $\mathbf{M g}^{2+}$ and $\mathrm{Ca}^{2+}$. Brain Res 289:293-303.

Koike T, Martin DP, Johnson EM (1989) Role of calcium channels in the ability of membrane depolarization to prevent neuronal death induced by trophic-factor deprivation: evidence that levels of internal calcium determine nerve growth factor dependence of sympathetic ganglion cell. Proc Natl Acad Sci USA 86:6421-6425.

Lankford KL, Letourneau P (1989) Evidence that calcium may control neurite outgrowth by regulating the stability of actin filaments. J Cell Biol 109:1229-1243.

Lankford KL, Letourneau P (1991) Roles of actin filaments and three sccond messenger systcms in short term regulation of chick dorsal root ganglion neurite outgrowth. Cell Motil Cytoskel, in press.

Letourneau P, Wessels NK (1974) Migratory cell locomotion versus nerve axon elongation. J Cell Biol 61:56-69.

Llinas $R$ (1979) The role of calcium in neuronal function. In: The neurosciences fourth study program (Schmidtt FO, Worden FG, eds), pp 555-571. Cambridge, MA: MIT Press.

Marasco WA, Beker EL, Oliver JM (1980) The ionic basis of chemotaxis: separation of cation requirements for neutrophile orientation and locomotion in a gradient of chemotactic peptide. Am J Pathol 98:749-768.

Marsh G, Beams HW (1946) In vitro control of growing chick nerve fibers by applied electric currents. J Cell Comp Physiol 27:139-157.

Mattson M, Kater SB (1987) Calcium regulation of neurite elongation and growth conc motility. J Ncurosci Res 7:4034-4043.

Mattson MP, Kater SB (1988) Excitatory and inhibitory neurotransmitters in the generation and degeneration of hippocampal neuroarchitecture. Brain Res 478:337-348.

Mattson MP, Taylor-Hunter A, Kater SB (1988a) Neurite outgrowth in individual neurons of a neuronal population is differentially regulated by calcium and cyclic AMP. J Neurosci 8:1704-1711.

Mattson MP, Guthrie PB, Kater SB (1988b) Intracellular messengers in the generation and degeneration of hippocampal neuroarchitecture. J Neurosci Res 21:447-464.

Mattson MP, Dou P, Kater SB (1988c) Outgrowth-regulating actions of glutamate in isolated hippocampal pyramidal neurons. J Neurosci 8:2087-2100.

Mattson M, Guthrie PB, Kater SB (1989a) A role for $\mathrm{Na}^{+}$-dependent calcium extrusion in protection against neuronal excitotoxicity. FASEB J 3:2519-2526.

Mattson MP, Murrain M, Guthrie PG, Kater SB (1989b) Fibroblast growth factor and glutamate: opposing roles in the generation and degeneration of hippocampal architecture. J Neurosci 9:3728-3738.

McBurney RN, Neering IR (1987) Neuronal calcium homeostasis. Trends Neurosci 10:164-169.

McCaig CD (1989) Studies on the mechanism of embryonic frog nerve orientation in a small applied electric field. J Cell Sci 93:723-730.

McCobb DP, Kater SB (1988a) Dopamine and serotonin inhibition of neurite elongation of different identified neurons. J Neurosci Res 19:19-26.

McCobb DP, Kater SB (1988b) Membrane voltage and neurotransmitter regulation of neuronal growth cone motility. Dev Biol 130: 599-609.

McCobb DP, Cohan CS, Connor JA, Kater SB (1988) Interactive effects of serotonin and acetylcholine on ncurite clongation. Neuron $1: 377-385$

Mills LR, Kater SB (1989) Integration of environmental and intracellular signals: the calcium hypothesis for the control of neuronal growth cones. In: Assembly of the nervous system (Landmesser L, ed), pp 65-80. New York: Liss.

Mills LR, Kater SB (1990) Neuron-specific and state-specific differences in calcium homeostasis regulate the generation and degeneration of neuronal architecture. Neuron 2:149-163.

Mitchison T, Kirschner M (1988) Cytoskeletal dynamics and nerve growth. Neuron 1:761-772.

Nishi R, Berg DK (1981) Effects of high $\mathrm{K}^{+}$concentration on the growth and development of ciliary ganglion neurons in cell culture. Dev Biol 87:301-307.

Patel NB, Poo M-m (1982) Orientation of ncuritc growth by cxtracellular electric fields. J Neurosci 2:483-496.

Patel NB, Poo M-m (1984) Perturbation of the direction of neurite growth by pulsed and focal electric fields. J Neurosci 4:2939-2947.

Patterson PH (1988) On the importance of being inhibited, or saying no to growth cones. Neuron 1:263-267.

Poenie M, Aderton J, Tsien RY, Steinhardt RA (1985) Changes in free calcium levels with stages in the cell division cycle. Nature 315: 147-149.

Polak KA, Edelman AM, Wasley JWF, Cohan CS (1991) A novel calmodulin antagonist, CGS 9343B, modulates calcium-dependent changes in neurite outgrowth and growth cone movements. J Neurosci $11: 534-542$.

Prusch RD (1986) Calcium and pinocytosis. In: The role of calcium in biological systcms, Vol 1 (Anghilcri LJ, Tuffct-Anghilcri AM, cds), pp 1219-2230. Boca Raton, FL: CRC.

Ramon y Cajal S (1890) A quelle epoque apparaissent les expansions des cellules nerveuses de la moelle epiniere du poulet. Anat Anz 5: 609-613, 631-639.

Rehder V, Jensen JR, Dou P, Kater SB (1991) A comparison of calcium homeostasis in isolated and attached growth cones of the snail Helisoma. J Neurobiol, in press.

Robson SJ, Burgoyne RD (1989) L-type calcium channels in the regulation of neurite outgrowth from rat dorsal root ganglion neurons in culture. Neurosci Lett 104:110-114.

Schliwa M, Euteneur U, Bulinski JC, Izant JC (1981) Calcium lability of cytoplasmic microtubules and its modulation by microtubule-associated proteins. Proc Natl Acad Sci USA 78:1037-1041.

Schubert D, Lacorbicre M, Whitlock C, Stallcup W (1978) Altcrations in the surface properties of cells responsive to nerve growth factor. Nature 273:718-721.

Schuch U, Lohse MJ, Schachner M (1989) Neural cell adhesion molecules influence second messenger systems. Neuron 3:13-20.

Silver RA, Lamb AG, Bolsover SR (1989) Elevated cytosolic calcium in the growth cone inhibits neurite elongation in neuroblastoma cells: correlation of behavioral states with cytosolic calcium concentration. J Neurosci 9:4007-4020.

Silver RA, Lamb AG, Bolsover SR (1990) Calcium hotspots caused by L-channel clustering promote morphological changes in neuronal growth cones. Nature 343:751-754.

Sobue K, Kanda K (1989) Alpha-actinins, calspectrin (brain spectrin or fodrin) and actin participate in adhesion and movement of growth cone. Neuron 3:311-319.

Song DK, Mykels DL, Kater SB (1990) Effects of a calpain inhibitor, EST on calcium ionophore A23187-induced changes in neurite outgrowth in isolated hippocampal pyramidal neurons. J Cell Biol 111: $244 a$.

Suarez-Isla BA, Pelto DJ, Thompson JM, Rapoport SI (1984) Blockers of calcium permeability inhibit neurite extension and formation of neuromuscular synapses in cell culture. Dev Brain Res 14:263-270.

Tolkovsky AM, Walker AE, Murrel RD, Suidan HS (1990) Calcium transients are not required as signals for long-term neurite outgrowth from cultured sympathetic neurons. J Cell Biol 110:1295-1306.

Tsien RY (1988) Fluorescence measurement and photochemical manipulation of cytosolic free calcium. Trends Neurosci 11:419-424.

Tsien RY (1989) Fluorescent indicators of ion concentrations. Methods Cell Biol 30:127-155. 